\title{
REUSO DE EFLUENTES EM TORRES DE RESFRIAMENTO
}

\author{
L.V. DURANTE ${ }^{1}$, A. TROMBETA ${ }^{1}$, E. R. A. PRADO ${ }^{1}$, \\ P. R. PARAÍSO ${ }^{1}$ e L. M. M. JORGE ${ }^{1}$
}

${ }^{1}$ Universidade Estadual de Maringá, Departamento de Engenharia Química

E-mail para contato: leydianedurante@hotmail.com/lmmj@deq.uem.br

\begin{abstract}
RESUMO - A água é um recurso natural que possui valores intangíveis. Sua iminente escassez tem gerado constante preocupação e levado o setor industrial a buscar alternativas para reduzir o consumo e investir em tecnologias para sua recuperação. Diante do exposto, foi realizada uma análise das principais correntes passíveis de reuso e avaliação de sua aplicabilidade nos processos fabris de um complexo agroindustrial. Neste contexto, foi proposta uma configuração de baixo custo para o polimento do efluente tratado da ETE com posterior reutilização na reposição de água de uma torre de resfriamento. A partir de modelos matemáticos obtidos de balanços de massa e de energia nas torres de resfriamento foi implantado, em plataforma Excell ${ }^{\circledR}$, um simulador de interface amigável, que possibilita o monitoramento do resfriamento evaporativo. Os resultados obtidos foram satisfatórios e apontam para a possibilidade de redução de $15 \%$ em relação ao volume de água captada de poços artesianos.
\end{abstract}

\section{INTRODUÇÃOO}

Muito embora o planeta tenha três quartos de sua superfície coberta pela água, deve-se levar em consideração que apenas uma pequena parcela, referente à água doce, pode ser utilizada para o desenvolvimento da maior parte das atividades humanas, sem a necessidade de se fazer grandes investimentos para a adequação das suas características físicas, químicas e/ou biológicas, aos padrões de qualidade exigidos para cada tipo de aplicação (MAYS, 1996 apud MIERZWA, 2002). Da água existente na Terra, 97\% consiste em água salgada e 3\% é de água doce. Destes 3\%, 76\% estão sob forma de gelo nas calotas polares. A minúscula parcela restante, que corresponde às águas subterrâneas e de superfície, ainda sofre todo tipo de agressão (DIAS, 2004). Um grande fator a ser considerado é que a distribuição de água no planeta não é homogênea. No Brasil, a região hidrográfica amazônica, considerada a maior bacia hidrográfica do mundo, detém cerca de $80 \%$ de toda a água doce disponível, onde se encontra o menor contingente populacional, restando apenas $20 \%$ para o restante do país, que concentra mais de $90 \%$ da população demográfica nacional (ANA, 2012). Desta forma, embora seja considerada como um recurso renovável, amplia-se a percepção de que a quantidade de água doce disponível na terra é limitada e sua qualidade está sob constante pressão, resultando em custos para sua obtenção e tratamento cada vez mais elevados.

Com a grande e constante evolução tecnológica, o crescimento da população e sua consequente mudança de hábitos, a atividade humana e industrial vem gradativamente ampliando sua capacidade de alteração no meio ambiente, principalmente no recurso água 
(DIAS, 2004). Em função da alta competitividade exigida em todos os segmentos do mercado, cada vez mais as empresas estão buscando sua modernização e aumento de produtividade. Como resultado, mais recursos naturais deverão ser utilizados e maiores quantidades de água serão necessárias para fim de manufatura, geração de energia térmica e refrigeração industrial.

De acordo com Hespanhol (1997), a utilização de tecnologias apropriadas para o desenvolvimento de fontes alternativas de água é, provavelmente, a única abordagem mais adequada para resolver o problema global da escassez deste recurso natural, juntamente com melhorias na eficiência do uso da água e com controle adequado para reduzir o seu consumo.

O reuso de água consiste no aproveitamento de águas previamente utilizadas, uma ou mais vezes, em alguma atividade humana, para suprir as necessidades de outros usos benéficos, inclusive o original (LAVRADOR FILHO 1987, apud BREGA FILHO; MANCUSO, 2003). Brega Filho e Mancuso (2003) expõem que é uma tecnologia desenvolvida em maior ou menor grau, dependendo dos fins a que se destina a água e de como ela tenha sido usada anteriormente.

A prática do reuso em sistemas industriais proporciona benefícios ambientais significativos, pois permite que um volume maior de água permaneça disponível para outros usos mais nobres. Em certas condições, pode reduzir a poluição hídrica por meio da minimização da descarga de efluentes (HESPANHOL et al., 2006). Os sistemas de reuso utilizam técnicas tradicionais de tratamento de água e tecnologias mais avançadas, em arranjos variados, que dependem das qualidades do efluente a ser tratado e da qualidade desejada para o reuso (CARVALHO E MACHADO, 2010).

Este trabalho teve como objetivos avaliar as características de duas correntes potenciais para o reuso (efluente tratado e rejeito de osmose reversa), de modo a propor seu reaproveitamento a partir de uma configuração com baixo custo em torres de resfriamento e realizar um estudo deste sistema de resfriamento a partir de balanços de massa e energia.

\section{BALANÇOS DE MASSA E DE ENERGIA}

O balanço de água de uma torre de resfriamento de recirculação aberta envolve quatro correntes principais. São elas: taxa de reposição de água ou make-up (M), taxa de evaporação (E), taxa de descarga ou purga (D) e taxa de arraste/respingos (A).

$$
M=E+A+D
$$

Uma vez que a fração mássica dos contaminantes na água perdida por arraste e na descarga são iguais $\left(x_{a}=x_{d}\right)$ e a fração mássica de contaminantes na água perdida por evaporação é igual a zero, o balanço material para os componentes, expressos em termos de concentração de sais dissolvidos ou outras impurezas pode ser descrito como:

$$
\mathrm{Mx}_{\mathrm{m}}=(\mathrm{A}+\mathrm{D}) \mathrm{x}_{d}
$$

em que $\mathrm{x}_{\mathrm{m}}$ e $x_{d}$ são as frações mássicas dos contaminantes na água de reposição e na purga, respectivamente. 
A variação da alcalinidade é descrita de acordo com relação experimental obtida através do acompanhamento da variação de seus valores com o ciclo de concentração. O cálculo da variação do pH pode ser realizado através da equação de Caplan (SILBERT, 2012).

$$
\mathrm{pH}=1,645 \log (\text { Alc. })+4,477
$$

O ciclo de concentração pode ser descrito como:

$$
\mathrm{c}=\frac{\text { concentração de sólidos dissolvidos na água de resfriamento }}{\text { concentração de sólidos dissolvidos na água de reposição }}
$$

O cálculo direto da taxa mássica de descarga (D) para um determinado ciclo de concentração pela equação fica:

$$
D=\frac{E}{(c-1)}-A
$$

As perdas por arraste e ação do vento (A), podem ser expressas como porcentagem da vazão de recirculação:

$$
\mathrm{A}=\mathrm{A} \% \frac{\mathrm{Q}}{100}
$$

em que A\% varia de acordo com o modelo e projeto de cada torre.

A taxa de evaporação (E) é obtida através de um balanço de energia na torre de resfriamento, juntamente com testes para obtenção dos parâmetros necessários para seu cálculo: temperaturas da água fria e da água quente, temperaturas de bulbo úmido do ar de entrada e de saída, temperatura de bulbo seco do ar de entrada, vazões de recirculação do líquido e do ar. A metodologia para o cálculo da taxa de evaporação foi desenvolvida em Visual Basic do Programa Microsoft Excel ${ }^{\circledR} 2010$ :

$$
E=G\left(\omega_{2}-\omega_{1}\right)
$$

em que $\left(\omega_{1}\right)$ e $\left(\omega_{2}\right)$ são as umidades absolutas do ar de entrada e de saída, respectivamente.

A taxa mássica de ar (G) é calculada pela equação que determina o valor de teste $\mathrm{L} / \mathrm{G}$ da norma ACT-105 do CTI (COOLING TOWER INSTITUTE, 2000), onde é necessária a utilização de um método iterativo para o cálculo da temperatura de bulbo úmido (Tbu) do ar de saída.

$$
(L / G)_{t}=(L / G)_{p}\left(\frac{L_{t}}{L_{p}}\right)\left(\frac{\text { pot }_{p}}{\text { pot }_{t}}\right)^{1 / 3}\left(\frac{\rho_{t}}{\rho_{p}}\right)^{1 / 3}\left(\frac{v_{t}}{v_{p}}\right)
$$

em que (L/G) é relação entre a taxa de fluxo de massa da água para o ar e os índices t e p referem-se aos dados de teste e de projeto, respectivamente. L é taxa mássica de água de recirculação, pot é potência do ventilador e $v$ e $\rho$ o são volume específico do ar e a densidade do ar, respectivamente. Os valores de projeto e de teste para o volume específico do ar (v) e densidade $(\rho)$, para torres de tiragem induzida, são avaliados nas condições de saída da torre. $\mathrm{O}$ ar de saída foi considerado saturado. 
A condição de restrição para as concentrações de sais na água de resfriamento é imposta pelo Índice de Saturação de Langelier (LSI), que indica a tendência à corrosão ou à incrustação.

$$
\mathrm{LSI}=\mathrm{pH}-\mathrm{pH}_{\mathrm{s}}
$$

em que $\mathrm{pH}$ é o $\mathrm{pH}$ medido $\mathrm{epH}_{\mathrm{s}}$ é o $\mathrm{pH}$ de saturação calculado. A determinação do $\mathrm{pH}_{\mathrm{s}}$ é realizada a partir dos teores de sólidos totais dissolvidos, da temperatura do meio aquoso, da concentração de cálcio (dureza cálcica) e da concentração de bicarbonatos (alcalinidade total).

\section{RESULTADOS E DISCUSSÕES}

\subsection{Análise das correntes}

Foram realizadas análises das correntes passíveis de reaproveitamento (efluente tratado e rejeito da osmose), cujos valores médios estão apresentados na Tabela 1. Estes valores foram comparados com os parâmetros recomendados por Blum (2003) e, então, analisados separadamente.

Tabela 1 - Resultado das análises físico-químicas das correntes potenciais para reuso

\begin{tabular}{|l|c|c|c|c|}
\hline Parâmetro & Unidade & Padrão ${ }^{*}$ & Efluente Tratado & Rejeito Osmose \\
\hline $\mathrm{pH}$ & - & $6,0-9,0$ & 7,38 & 8,20 \\
\hline Alcalinidade Total & $\mathrm{ppm} \mathrm{CaCO}_{3}$ & 350 & 149,20 & 308,00 \\
\hline Dureza Total & $\mathrm{ppm} \mathrm{CaCO}_{3}$ & 650 & 48,42 & 75,63 \\
\hline Dureza de Cálcio & $\mathrm{ppm} \mathrm{CaCO}$ & & 35,82 & 53,63 \\
\hline Cloreto & $\mathrm{ppm}$ & 500 & 233,52 & 17,90 \\
\hline Ortofosfato & $\mathrm{ppm}$ & & 0,15 & 1,78 \\
\hline Fosfato total & $\mathrm{ppm}$ & 4 & 0,23 & $\mathrm{NA}$ \\
\hline Sílica Alto Teor & $\mathrm{ppm}$ & 50 & 19,37 & 120,31 \\
\hline Condutividade & $\mu \mathrm{S} / \mathrm{cm}$ & & $1.549,80$ & 609,50 \\
\hline Ferro Total & $\mathrm{ppm}$ & 0,5 & 0,04 & 0,05 \\
\hline Zinco Total e Solúvel & $\mathrm{ppm}$ & & 0,16 & $\mathrm{NA}$ \\
\hline Turbidez & $\mathrm{NTU}$ & & 1,20 & 0,98 \\
\hline Sulfato & $\mathrm{ppm}$ & 200 & 187,80 & $\mathrm{NA}$ \\
\hline Cor Aparente & $\mathrm{un} . \mathrm{Pt} / \mathrm{Co}$ & & 6,80 & 0,25 \\
\hline DQO & $\mathrm{mg} / \mathrm{LO}$ & 75 & 25,25 & 30,00 \\
\hline
\end{tabular}

(*) padrões de qualidade recomendados por Blum (2003) para a água de reposição de sistemas de resfriamento

$\mathrm{NA}=$ não avaliado

Corrente 1 - Efluente Tratado

Analisando as características do efluente tratado na saída do decantador, não é observada nenhuma restrição quanto aos parâmetros quantificados. Porém, os valores de cloreto e sulfato merecem uma análise em particular. O valor de DQO apresentado na Tabela 1 para o efluente do decantador $(25,25 \mathrm{mg} / \mathrm{L})$ indica que é possível fazer o reuso dessa água. 
A quantidade de íons cloreto e sulfato no efluente tratado (233,52 ppm e 187,80ppm, respectivamente), apesar de inferiores aos limite requeridos (500 ppm e 200 ppm), são considerados elevados. De acordo com Gentil (2003), o cloreto é um dos sais que mais influenciam no processo de corrosão e seu efeito deve-se ao fato de este sal ser um eletrólito forte, ocasionando, portanto, o aumento de condutividade, que é fundamental no mecanismo eletroquímico de corrosão.

\section{Corrente 2 - Rejeito da Osmose}

$\mathrm{O}$ uso do rejeito da osmose torna-se restritivo em função do teor de sílica apresentado (120,31 ppm). A alcalinidade (308,00 ppm $\left.\mathrm{CaCO}_{3}\right)$, aproxima-se ao valor limite estabelecido (350 ppm $\mathrm{CaCO}_{3}$ ). Em DREW (1979) encontra-se que incrustações de sílica pura não são encontradas com frequência em sistemas de refrigeração. No entanto, uma vez formadas, são de difícil remoção. A precipitação de cálcio e magnésio com sílica pode provocar incrustações resistentes à remoção por processos químicos. A formação de tais incrustações pode ser evitada limitando-se os níveis de sílica a cerca de $175 \mathrm{ppm}$ na água circulante. A alcalinidade está relacionada com a presença de bicarbonatos, carbonatos e hidróxidos. Para valores de $\mathrm{pH}$ na faixa de 4,4 a 8,3, seu valor deve-se basicamente à presença de bicarbonatos $\left(\mathrm{HCO}_{3}^{-}\right)$. $\mathrm{O}$ valor do $\mathrm{pH}(8,2)$, de acordo com a Tabela 1, apesar de também estar dentro da faixa recomendada $(6,0$ a 9,0), deve ser avaliado pelo fato de que faixas mais elevadas de $\mathrm{pH}$ aumentam a tendência à formação de incrustações (DREW, 1979).

Após um comparativo entre as características das correntes passíveis de reuso (efluente tratado e rejeito da osmose) com os dados limites para água encontrados na literatura, aliados ao estudo das características do sistema (temperaturas, metalurgias, etc.), verifica-se que o efluente tratado é a alternativa mais interessante para estudo como água de reuso. No entanto, é necessária a utilização de um sistema de tratamento para esta corrente, adequação no programa de tratamento químico, automação do sistema e alteração nos controles realizados com o intuito de minimizar os principais problemas causados em sistemas abertos com recirculação, tais como: incrustação, depósitos, corrosão e proliferação microbiológica.

\subsection{Proposta de Configuração para o Reaproveitamento}

Com relação aos altos teores de íons cloreto e sulfato apresentado para o efluente tratado (Tabela 1), por tratar-se de íons agressivos, é necessário desenvolver um programa de tratamento específico e projetar a redução desses íons com substituições de químicos na planta de tratamento de efluentes. Os íons cloreto são altamente corrosivos. A origem dos íons cloreto está na utilização de ácido clorídrico para controle de $\mathrm{pH}$ do tratamento físico químico da ETE. Sua substituição por ácido sulfúrico iria reduzir sensivelmente o teor de cloretos, porém poderia causar uma elevação no teor de sulfato. No entanto, o íon sulfato é muito menos corrosivo e há possibilidade de controlar possíveis problemas de deposição com tratamento químico. Já a origem dos íons sulfato deve-se à utilização do sulfato de alumínio como coagulante no sistema de tratamento físico-químico da unidade. Há a possibilidade de diminuição destes íons mediante a substituição do coagulante utilizado por um coagulante com menores teores de sulfato ou com íons menos agressivos.

O sistema proposto para reuso do efluente tratado do decantador está ilustrado na Figura 1. Para garantir a estabilização da água de alimentação do sistema de resfriamento em termos 
de turbidez, propõe-se a instalação de um sistema de cloração para controle microbiológico e oxidação de metais, como ferro e manganês, e posterior filtração com areia com o objetivo de remover sólidos em suspensão. Para proteção do sistema de filtração, é interessante a instalação de um turbidímetro em linha antes do filtro, orientado para desviar o fluxo em caso de um possível problema operacional no decantador. Por fim, tubulação e bombas seriam necessárias para enviar o efluente ao sistema de resfriamento.

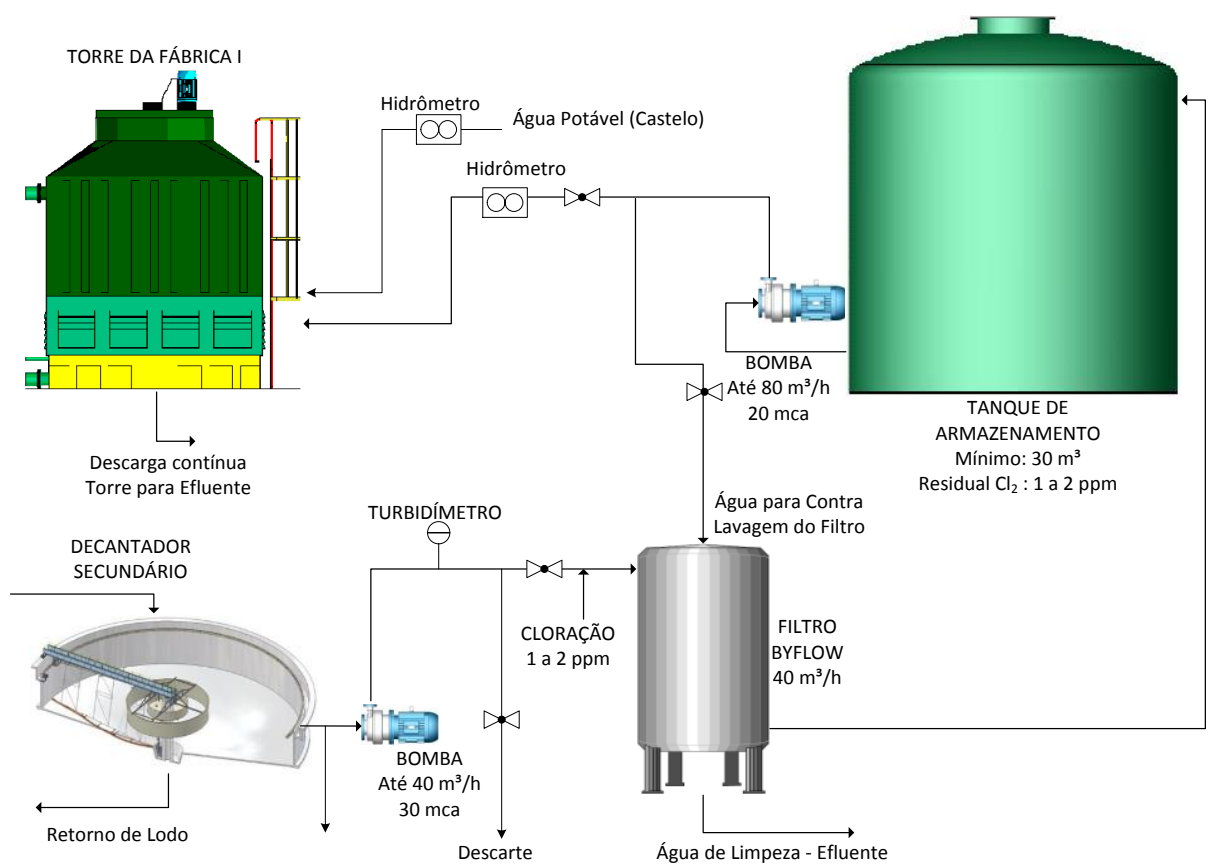

Figura 1 - Fluxograma simplificado da instalação necessária para que o reuso seja possível

\subsection{Cálculo da taxa de água necessária para a reposição do sistema}

O balanço material da torre de resfriamento é realizado pelo simulador de análise dos ciclos de concentração, apresentado na Figura 2. Esta planilha permite fazer a simulação do reuso de água para uma composição de diferentes correntes. Nesta simulação, é possível realizar um controle permanente do comportamento dos diversos componentes presentes na água de refrigeração. Não existem limitações de ciclos de concentração, de teores de sílica, cálcio, magnésio, $\mathrm{pH}$, alcalinidade, temperatura, etc. Existe somente a limitação do Índice de Saturação de Langelier (LSI), que é consequência de uma interação dinâmica de diversos parâmetros. 


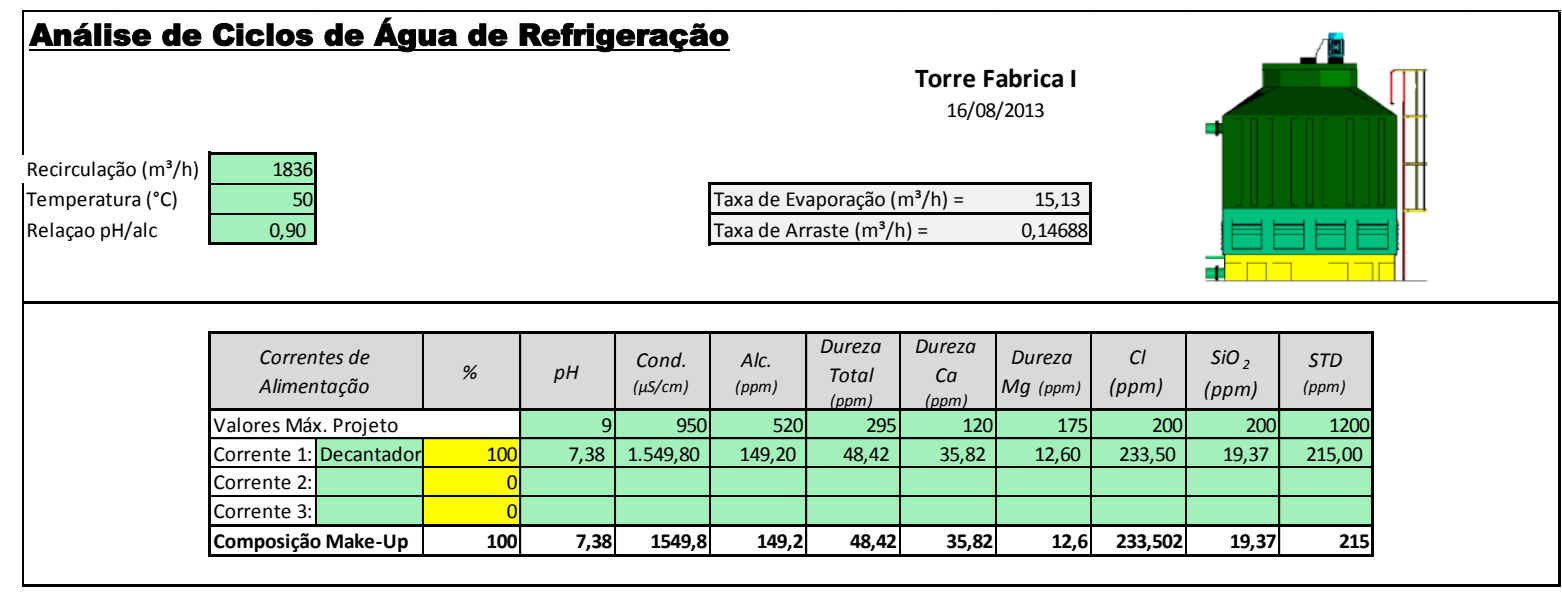

\begin{tabular}{|c|c|c|c|c|c|c|c|c|c|c|c|c|c|c|c|}
\hline \multicolumn{16}{|c|}{ CONTROLE DOS PARÂMETROS E CORRENTES A CADA CICLO DE CONCENTRAÇÃO } \\
\hline \multirow[b]{2}{*}{ CICLOS } & \multirow[b]{2}{*}{$p H$} & \multirow{2}{*}{$\begin{array}{l}\text { Cond. } \\
(\mu \mathrm{S} / \mathrm{cm})\end{array}$} & \multirow[b]{2}{*}{$\begin{array}{l}\text { Alc. } \\
\text { (ppm) }\end{array}$} & \multirow{2}{*}{$\begin{array}{c}\text { Dureza } \\
\text { Total } \\
\text { (ppm) }\end{array}$} & \multirow{2}{*}{$\begin{array}{l}\text { Dureza } \\
\text { de Ca } \\
\text { (ppm) }\end{array}$} & \multirow{2}{*}{$\begin{array}{c}\text { Dureza } \\
\text { de } M g \\
\text { (ppm) }\end{array}$} & \multirow[b]{2}{*}{$\mathrm{Cl}(p p m)$} & \multirow{2}{*}{$\begin{array}{c}\mathrm{SiO} 2 \\
(\mathrm{ppm})\end{array}$} & \multirow[b]{2}{*}{$S T D(p p m)$} & \multirow[b]{2}{*}{$L S I$} & \multirow{2}{*}{$\begin{array}{c}\text { Descarga } \\
(\mathrm{m} 3 / \mathrm{h})\end{array}$} & \multicolumn{4}{|c|}{ Makeup (m3/h) } \\
\hline & & & & & & & & & & & & Total & \begin{tabular}{|c|}
$\begin{array}{c}\text { Decanta } \\
\text { dor }\end{array}$ \\
\end{tabular} & - & \\
\hline MAKE UP & 8,1 & $1.549,8$ & 149,2 & 48,4 & 35,8 & 12,6 & 233,5 & 19,4 & 215,0 & 0,4 & - & - & - & - & - \\
\hline 1,5 & 8,3 & $2.324,7$ & 201,4 & 72,6 & 53,7 & 18,9 & 350,3 & 29,1 & 322,5 & 0,9 & 30,1 & 45,4 & 45,4 & - & - \\
\hline 2,0 & 8,5 & $3.099,6$ & 268,6 & 96,8 & 71,6 & 25,2 & 467,0 & 38,7 & 430,0 & 1,3 & 15,0 & 30,3 & 30,3 & - & - \\
\hline 2,5 & 8,6 & $3.874,5$ & 335,7 & 121,1 & 89,6 & 31,5 & 583,8 & 48,4 & 537,5 & 1,7 & 9,9 & 25,2 & 25,2 & - & - \\
\hline 3,0 & 8,8 & $4.649,4$ & 402,8 & 145,3 & 107,5 & 37,8 & 700,5 & 58,1 & 645,0 & 1,9 & 7,4 & 22,7 & 22,7 & - & - \\
\hline 3,5 & 8,9 & $5.424,3$ & 470,0 & 169,5 & 125,4 & 44,1 & 817,3 & 67,8 & 752,5 & 2,2 & 5,9 & 21,2 & 21,2 & - & - \\
\hline 4,0 & 9,0 & $6.199,2$ & 537,1 & 193,7 & 143,3 & 50,4 & 934,0 & 77,5 & 860,0 & 2,3 & 4,9 & 20,2 & 20,2 & - & - \\
\hline 4,5 & 9,1 & $6.974,1$ & 604,3 & 217,9 & 161,2 & 56,7 & $1.050,8$ & 87,2 & 967,5 & 2,5 & 4,2 & 19,5 & 19,5 & - & - \\
\hline 5,0 & 9,1 & $7.749,0$ & 671,4 & 242,1 & 179,1 & 63,0 & $1.167,5$ & 96,9 & $1.075,0$ & 2,7 & 3,6 & 18,9 & 18,9 & - & - \\
\hline 5,5 & 9,2 & $8.523,9$ & 738,5 & 266,3 & 197,0 & 69,3 & $1.284,3$ & 106,5 & $1.182,5$ & 2,8 & 3,2 & 18,5 & 18,5 & - & - \\
\hline 6,0 & 9,3 & $9.298,8$ & 805,7 & 290,5 & 214,9 & 75,6 & $1.401,0$ & 116,2 & $1.290,0$ & 2,9 & 2,9 & 18,2 & 18,2 & - & - \\
\hline 6,5 & 9,3 & $10.073,7$ & 872,8 & 314,7 & 232,8 & 81,9 & $1.517,8$ & 125,9 & $1.397,5$ & 3,1 & 2,6 & 17,9 & \begin{tabular}{ll|}
17,9 \\
\end{tabular} & - & - \\
\hline 7,0 & 9,4 & $10.848,6$ & 940,0 & 338,9 & 250,7 & 88,2 & $1.634,5$ & 135,6 & $1.505,0$ & 3,2 & 2,4 & 17,7 & 17,7 & - & - \\
\hline 7,5 & 9,4 & $11.623,5$ & $1.007,1$ & 363,2 & 268,7 & 94,5 & $1.751,3$ & 145,3 & $1.612,5$ & 3,3 & 2,2 & 17,5 & 17,5 & - & - \\
\hline 8,0 & 9,5 & $12.398,4$ & $1.074,2$ & 387,4 & 286,6 & 100,8 & $1.868,0$ & 155,0 & $1.720,0$ & 3,4 & 2,0 & 17,3 & 17,3 & - & - \\
\hline 8,5 & 9,5 & $13.173,3$ & $1.141,4$ & 411,6 & 304,5 & 107,1 & $1.984,8$ & 164,6 & $1.827,5$ & 3,4 & 1,9 & 17,2 & 17,2 & - & - \\
\hline 9,0 & 9,5 & $13.948,2$ & $1.208,5$ & 435,8 & 322,4 & 113,4 & $2.101,5$ & 174,3 & $1.935,0$ & 3,5 & 1,7 & 17,0 & 17,0 & - & - \\
\hline 9,5 & 9,6 & $14.723,1$ & $1.275,7$ & 460,0 & 340,3 & 119,7 & $2.218,3$ & 184,0 & $2.042,5$ & 3,6 & 1,6 & 16,9 & 16,9 & - & - \\
\hline 10,0 & 9,6 & $15.498,0$ & $1.342,8$ & 484,2 & 358,2 & 126,0 & $2.335,0$ & 193,7 & $2.150,0$ & 3,7 & 1,5 & 16,8 & 16,8 & - & - \\
\hline 12,5 & 9,8 & $19.372,5$ & $1.678,5$ & 605,3 & 447,8 & 157,5 & $2.918,8$ & 242,1 & $2.687,5$ & 4,0 & 1,2 & 16,4 & 16,4 & - & - \\
\hline 15,0 & 9,9 & $23.247,0$ & $2.014,2$ & 726,3 & 537,3 & 189,0 & $3.502,5$ & 290,6 & $3.225,0$ & 4,3 & 0,9 & 16,2 & 16,2 & - & - \\
\hline
\end{tabular}

Figura 2 - Planilha de análise de ciclos de concentração de água de refrigeração

O potencial de redução no consumo de água captada, considerando uma vazão de reposição média de $25,0 \mathrm{~m}^{3} / \mathrm{h}$, é de aproximadamente $198.000 \mathrm{~m}^{3}$ ao ano. Este valor foi estimado multiplicando-se a taxa de reposição $\left(25,0 \mathrm{~m}^{3} / \mathrm{h}\right)$ pelo número de horas trabalhadas no ano (7920 h).

\section{CONSIDERAÇÕES FINAIS}

A composição química da água de reposição da torre de resfriamento é de suma importância para a o controle e otimização do sistema, influenciando diretamente na taxa de purga, dos ciclos de concentração e, consequentemente, na taxa de reposição da torre. Desta maneira, as principais variáveis que podem influenciar o processo foram correlacionadas e utilizadas no balanço de massa da torre de resfriamento utilizando programação em plataforma Excel $^{\circledR}$ 2010. Este simulador permitiu o acompanhamento dos ciclos de concentração e o comportamento dos diversos componentes presentes na água para a condição de reposição proposta.

O trabalho apresentou uma alternativa de reuso com baixo custo de implantação e também com baixo custo operacional, com elevado potencial de ganho. O potencial de 
redução no consumo de água subterrânea captada, considerando uma vazão de reposição média de $25,0 \mathrm{~m}^{3} / \mathrm{h}$, é de aproximadamente $198.000 \mathrm{~m}^{3}$ ao ano, viabilizando este montante para usos mais nobres (consumo humano, produção industrial, etc.).

\section{REFERENCIAS}

AGÊNCIA NACIONAL DE ÁGUAS. Conjuntura dos recursos hídricos no Brasil: informe 2012. Brasília: ANA, 2012. Disponível em:

<http://arquivos.ana.gov.br/imprensa/arquivos/Conjuntura2012.pdf>. Acesso em: 03/07/2012

BLUM, J. R. C. Critérios e padrões de qualidade da água. In: MANCUSO, P. C. S.; SANTOS, H. F. (Ed.). Reuso de Água. $1^{a}$ ed. São Paulo: Manole, 2003.

BREGA FILHO, D.; MANCUSO, P. C. S. Conceito de Reuso de Água. In: MANCUSO, P. C. S.; SANTOS, H. F. (Ed.). Reuso de Água. $1^{a}$ ed. São Paulo: Manole, 2003.

COOLING TOWER INSTITUTE. CTI Code ATC-105: acceptance test code for water cooling towers. USA, 2000.

CARVALHO, D. D.; MACHADO, B. J. F. Reuso de Efluentes em Torres de Resfriamento Estudo Conceitual: Aeroporto Internacional do Rio de Janeiro. Acta Scientiarum Technology. Maringá, v.32, 2010.

DIAS, G. F. Educação Ambiental: Princípios e Práticas. 9 ed. São Paulo: Gaia, 2004.

DREW PRODUTOS QUÍMICOS. Princípios de tratamento de água industrial. São Paulo, 1979.

GENTIL, V. Corrosão. 4. Ed. Rio de Janeiro: LTC, 2003.

HESPANHOL, I. Wastewater as a Resource. In: HELMER, R.; HESPANHOL, I. Water Pollution Control - A Guide to the Use of Water Quality Management. WHO/UNEP, 1997.

HESPANHOL, I.; MIERZWA J.C.; RODRIGUES, L. D. B.; SILVA, M. C. C. Manual de Conservação e Reuso de Água na Indústria. $1^{\mathrm{a}}$ ed. Rio de Janeiro: DIM, 2006.

LAVRADOR FILHO, J. Contribuição para o entendimento do reuso planejado da água e algumas considerações sobre suas possibilidades no Brasil. Dissertação de Mestrado Escola Politécnica de São Paulo, Universidade de São Paulo. São Paulo, 1987.

MAYS, L. W. Water Resources: An Introduction. In: MAYS, L.W (Ed.). Water Resources Handbook. 1st ed. Arizona: McGRAW-HILL, 1996.

MIERZWA, J. C. O uso racional e o reuso como ferramentas para o gerenciamento de águas e efluentes na indústria - estudo de caso da Kodak Brasileira. Tese de Doutorado - Escola Politécnica da Universidade de São Paulo. São Paulo, 2002.

SILBERT. W-Index - Water Index Calculations. Disponível em: <http://www.silbert.org/Windex-Spreadsheet.pdf>. Acesso em: 18/07/2012. 